3 Research Square

\title{
Metabolomics Reveals Ecological Significance of Secondary Metabolites in Scutellaria baicalensis under drought stress.
}

Bo Li

Heilongjiang University of Chinese Medicine

\section{Wei Cong}

Heilongjiang University of Chinese Medicine

\section{Bin Wang}

Suihua University

Hongwei Du

Heilongjiang University of Science and Technology

Ai-hua Zhang

Heilongjiang University of Chinese Medicine

Xiang-Cai Meng ( $\nabla$ mengxiangcai000@163.com )

Heilongjiang University of Chinese Medicine

\section{Research article}

Keywords: Scutellaria baicalensis, metabolomics, reactive oxygen species, antioxidant enzymes, secondary metabolite

Posted Date: May 23rd, 2020

DOl: https://doi.org/10.21203/rs.3.rs-23642/v2

License: (9) This work is licensed under a Creative Commons Attribution 4.0 International License. Read Full License 


\section{Abstract}

Background: Plant have to face the more environmental stress than animal which can dodge unfavourable circumstances by moving about, it is inevitable that the reactive oxygen species(ROS), as a product of stress, are massive generated. Excessive ROS with a powerful oxidizability under stress could do harm to the protein, including enzymes. So it is impossible to eliminated too much ROS only by antioxidant enzymes. Plant have evolved a secondary metabolism as peculiar additional pathway, but the biosynthesis of secondary metabolites would be extremely costly due to the consumption of much material and energy during suitable condition, secondary metabolism are augmented only after the stress befall, meaning the secondary metabolites vary according to the ecological environment.

Results: Using UHPLC -ESI-Q-TOF-MS/MS analysis, a total of 24 differential compounts in root of Scutellaria baicalensis were identified between the drought and suitable condition. Based on Results of ttest analysis $\varangle P \llbracket 0.05 \bigotimes$ between various groups, ions whose VIP value $\geqq 2$, the most significant differential chemical markers of the drought condition were citric acid, shikimic acid, baicalin, wogonoside, baicalein, wogonin, 3,5,7,2',6'-pentahydroxyflavanone, 5,2',6'-trihydroxy-7,8 -dimethoxyflavone, chrysin, eriodictyol, 5,8-dihydroxy-6,7-dimethoxy flavone, highlighting that most of them were free flavonoids with many phenolic hydroxyl group of flavonoids, with a characteristic of higher avtivities.

Conclusions: The diversity of secondary metabolites plays a crucial role, S. baicalensis modified the ability to eliminate ROS and matained the equilibrium of ROS through the biosynthesis and convertion between these flavonoid which contain many compounts, like an intricate buffer solution.

\section{Background}

The animal subsist by moving to dodge unfavourable circumstances, but the plant have to face the various adversity such as the high-temperature, drought, low soil fertility, et al. Under the unfavourable condition the light energy which the chlorplasts absorbed is incompatible with that of capture $\mathrm{CO}_{2}$, leading to overcapacity of light energy, besides, the closed stomata arising from the increased abscisic acid under adversity blocked $\mathrm{O}_{2}$ emissions outward, and was reduced to $\mathrm{O}_{2}{ }_{2}$ (Mehler reation) ${ }^{[1]}$. $\mathrm{O}_{2}{ }_{2}$ can be convered into $\cdot \mathrm{OH}, \mathrm{H}_{2} \mathrm{O}_{2}$. They are named as reactive oxygen species(ROS) due to their powerful oxidation. ROS can modify the structures of protein, including enzymes, by affecting the disulfide bridges, and regulate various metabolism. Suitable level of ROS can act as messengers and regulate various physiological responses in plants ${ }^{[2-3]}$, but once ROS is over-produced, the redundant ROS can alter adjacent molecular configuration, and lead to reduce the cell-membrane stability, DNA strand distruction, protein crosslinking, peptide chains break, et al, with a result of metabolic disorder, even cell death ${ }^{[4-5]}$. It have been confirmed that increased ROS is a result of unfavourable circumstances ${ }^{[6-7]}, 0{ }^{\circ}{ }_{2}$ with 3 fold increase, $\mathrm{H}_{2} \mathrm{O}_{2}$ with 10 fold increase under certain condition ${ }^{[8-9]}$. Because of comparatively stable and weaker oxidation, $\mathrm{H}_{2} \mathrm{O}_{2}$ can be long-distance transported and become as a signal to regulate metabolism ${ }^{[10-11]}$. 
ROS resulting from unfavourable circumstances are eliminated mainly by antioxidant enzyme, including superoxide dismutase(SOD), catalase(CAT), peroxidase (POD), et al, and secondary metabolites, including carotenoids, tocopherols, and phenolics et al. $\mathrm{O}_{2}{ }_{2}$ is dismutated to $\mathrm{H}_{2} \mathrm{O}_{2}$ either spontaneously or by SOD, and then dismutated into $\mathrm{H}_{2} \mathrm{O}_{2}$ and $\mathrm{O}_{2}$ by CAT or POD. The ROS would not do harm to them under suitable level. However, the antioxidant enzyme are also protein, SOD with 2 subunits, CAT with 4 subunits, their some -SH groups which maintain the secondary structure and tertiary structure are liable to be injured if the plant be in severe abiotic stresses ${ }^{[12]}$, therefore, the plant can not survive only by the antioxidant enzymes, the secondary metabolism are indispensable.

The secondary metabolites in a plant are numerous, by Ultra-High-Performance Liquid Chromatography a total of 447 metabolites in Isatis indigotica Fortune, 128 in American ginseng root, 132 in

Scutellariabaicalensis, 122 in Moringa oleifera leaves were identified ${ }^{[13-16]}$, most of them are secondary metabolites. Their activities differ from each other, their proportion varied according to the changing environmental conditions ${ }^{[17]}$. Why do plant contains so many secondary metabolites? What is the connection between them? Drought is one of the most severe abiotic stresses in plant growth and development. Scutellaria baicalensis Georgi distributed throughout semi-arid steppe, its root is rich in various flavonoids with diverse structure ${ }^{[18]}$, and have anti-inflammatory, anti-tumor, and anti-HIV activities ${ }^{[19]}$. Drought is a main factor affecting the flavonoids in S. baicalensis ${ }^{[20]}$. At adverse environmental conditions, plants produce various kinds of primary and secondary metabolites to protect themselves.

Metabolomics, an untargeted biochemical approach to monitor the metabolites, is a research field used to acquire comprehensive information on the varied metabolites. Quantitative plant metabolomics, can improve our understanding of plant biochemistry and metabolism under both normal and stress conditions ${ }^{[21-22]}$, has been considered as the most promising approaches for the detection of primary and secondary metabolites in abiotic stresses ${ }^{[23-24]}$. Here, based on the difference before and after the stress we investigated the biological significance of flavonoids in S. baicalensis under water deficit conditions.

\section{Results}

\section{Identification of Chemical Markers in Radix Scutelariae}

MassLynx V4.1was employed for the analysis of the chemical constituents of Radix Scutelariae. The chemical composition was elucidated by the spectral information obtained from secondary ion mass spectrometry, which was cross-referenced with the retention time, mass-to-charge ratio, molecular weight, structural formula and elemental composition of known ingredients in Radix Scutelariae.On the basis of the VIP results, the candidate ions between the slight drought, the severe drought, and the control were identified tentatively.

When taking the identification of baicalin as an example, in positive mode, the ion (RT =4.92 $\mathrm{min}$ and $\left.[\mathrm{M}+\mathrm{H}]^{+}=447.12\right)$ detected in the slight drought -treated sample was calculated to be $\mathrm{C}_{21} \mathrm{H}_{19} \mathrm{O}_{11}$ based on 
the elemental composition, fractional isotope abundance, and Chemspider database information. The main MS/MS fragment ions of peak 9 were $m / z 271$ and $m / z 253$, indicating that the fragments may be $\mathrm{C}_{15} \mathrm{H}_{11} \mathrm{O}_{5}{ }^{-}$and $\mathrm{C}_{15} \mathrm{H}_{9} \mathrm{O}_{4}{ }^{-}$, which could indicate the loss of glucuronic acid (176 Da) and $\mathrm{H}_{2} \mathrm{O}_{2}(25 \mathrm{Da})$, respectively. With this integrated information, the ion was finally confirmed to be that of baicalin (Fig. 1).The corresponding mass spectrums and related structures were shown in Fig.1. According to the above-mentioned analytical method, a total of 24 chemical markers that were differentially expressed between the two Radix Scutelariae treatment groups were successfully identified, including 18 candidate ions in positive ion mode and 6 candidate ions in negative mode. Using Waters Masslynx software, we finally confirmed their identities with MS/MS data. UPLC-HDMS chromatograms of Scutellaria root in positive ion mode and in negative ion mode are shown in Fig. 2. Detailed information on the identified components is shown in Table 1.

\section{Characteristic Multivariate Metabolomic Data Analysis}

The PCA model was used to identify the difference in metabolites between the slight drought, the severe drought, and the control groups. The PCA score plots are shown in Fig.3. OPLS-DA was used to discriminate between the groups as well. As shown in Fig. 4, the group difference were clearly divided into three regions, indicating that there were significant chemical differences between them, and the established metabolomics method could successfully characterize the chemical characteristics. VIP values are commonly used to evaluate the contribution of variables in OPLS-DA. Based on the results of the t-test $(P \otimes 0.05)$ between groups, ions with VIP values $\geq 2$ were selected and regarded as the most significant differential chemical markers between the severe drought and the control. With this, Shikimic Acid, Citric acid, 3,5,7,2',6'-Pentahydroxyflavanone, Eriodictyol, Baicalin, Wogonoside, 5,2',6'-Trihydroxy -7,8- dimethoxyflavone, Baicalein, Wogonin, Chrysin, 5,8-Dihydroxy-6,7- dimethoxyflavone presented a significant differences. As shown in Fig. 6.

\section{Discussion}

\section{Drought increased secondary metabolism}

In this paper, only two primary metabolites were observed in the mass spectral data.Citric acid, a major substance in the tricarboxylic acid cycle, decreased remarkably to the continuous, incremental drought, indicating that the primary metabolism was weaked. The shikimic acid from which various flavonoids originated is a branch point of the primary and the secondary metabolic pathways, the decreased citric acid content and the increased shikimic acid content indicating that the secondary metabolism was enhanced, with a result of increasing secondary metabolites, a total of 9 secondary motabolites being all increased under the slight drought.

The shikimic acid located upstream of the citric acid, the Fig. 5 showed the shikimic acid are almost equal the severe drought, besides, the citric acid in the severe drouht decreases heavily, which mean that more shikimic acid should be tranformed into secondary metabolites. But except for 5,2',6'-Trihydroxy-7,8- 
dimethoxyflavone, all the severe drought below the slight drought, which may be due to excessive drought, it was very probable that the $S$. baicalensis produce more ROS under the severe drought, some secondary metabolites react with ROS and be consumed ${ }^{[25-26]}$.

\section{Biological significance of varied compounds}

Two features of these increased secondary metabolites invited our special attention. First. the molecular structure of the secondary metabolites dictated the biological effect by the number and sites of the phenolic hydroxyl groups in flavonoids. The molecular structure diagram of the flavonoids was shown in Fig. 7. It has been proved that the number of hydroxyl groups on the B ring directly impact the activity, which is also markedly enhanced when a double bond is introduced into the $C$ ring ${ }^{[27]}$. The hydroxyl group at positions $\mathrm{C}-5$ and $\mathrm{C}-7$ together in the $\mathrm{A}$ ring, as well as the $\mathrm{C}-3^{\prime}, \mathrm{C}-\mathrm{4}^{\prime}$ and $\mathrm{C}-5^{\prime}$ sites, on the $\mathrm{B}$ ring can all increase the activities obviously ${ }^{[28]}$; , in another position such as $\mathrm{C}-6$ can also increase the activity [29-30], another study showed that baicalein is more than 7 times more bioavailable than baicalin due to hydrophilic variations ${ }^{[31]}$. Secondly, except for the baicalin and the wogonoside, the other flavonoids were free flavonoids, not a saccharides derivatives. The composite enzymes of flavonoids biosynthesis located at endoplasmic reticulum, it is difficult for flavonoid glycosides to permeate freely into and out of the biomembrane with phospholipid bilayer due to hydrophilic saccharides. The biomembranes of animals and plants are the same; it has been proven that baicalein is $2 \sim 5$ times more antibiotically active than baicalin and 1 3 times better at inhibiting IL-1 $\beta$ converting enzymes ${ }^{[31]}$, a study showed that the activities of flavanone disappear when a sugar moiety is introduced into the A ring ${ }^{[27]}$., Flavonoid glycosides therefore are regarded as superfluous flavonoids; when required, they work mainly after conversion into free flavonoids ${ }^{[26]}$. It's very interesting that above mentioned secondary metabolites are all higher active, and lower contents, meaning the effect of compositions with a lower content can not be ignored.

ROS increases rapidly under stress. Whether overabundance or shortage, is harmful, depends on the delicate equilibrium between production and scavenging ${ }^{[12]}$, maintained by antioxidant. Under severe stress, the secondary metabolites would highlight, be coordinated with the ROS. The more ROS was produced, the higher the flavonoids activity. The regulation of flavonoids activities were performed through the biosynthesis and interconvertion between these flavonoid. For one case of baicalein or wogonin, if the ROS became higher, the chrysin only with C-5 and C-7 hydroxylation could also be added a hydroxyl or methoxy group, as well as baicalin and wogonoside were removed a glucuronic acid by baicalein7-0-glucuronosyl transferase or $\beta$-glucuronidase, and converted rapidly into the baicalein or wogonin with higher activities ${ }^{[32]}$, and vice versa. From the Fig. 5 such pathway was probably numerous.

\section{Conclusions}

The diversity of secondary metabolites plays a crucial role. A variety of secondary metabolites in $S$. baicalensis assembled into a complex with flexible proportion, modified the ability to eliminate redundant 
ROS and matained the equilibrium of ROS through the biosynthesis and convertion between these flavonoid, like an intricate buffer solution as quickly, delicately as possible.

\section{Methods}

\section{Plant Materials and Reagents}

The Scutellaria baicalensis Georgi, identified by Prof Xiang-cai Meng, were collected from the medical plants garden in Heilongjiang University of Chinese medicine. A total of 18 plants of 2 years were tranplanted into 3 flowerpots in May 2018, 6 plants every one. The flowerpots were slice the bottom off, then deposited underground, grew naturally without any intervention. In October(Temperature at around $10^{\circ} \mathrm{C}$ ), pulled the flowerpots out from the earth, put the plastic sheeting under the bottom to insulate soil water, then returned to original position. The slight drought treatment: Collected the sample when topsoil is around $2 \mathrm{~cm}$; the severe drought treatment: Collected the samples when topsoil is around $7 \mathrm{~cm}$; the control: Keep the soil moist. A total of 5 plants be selected from a flowerpot, washed the dirt off, removed the xylem, freeze-dried, and then grinded into a fine powder, respectively. A voucher specimen(S20181005) was deposited at the College of Pharmacy, Heilongjiang University of Chinese Medicine, China.

Reagents: Acetonitrile, HPLC grade, was obtained from Merck (Darmstadt, Germany); methanol (HPLC grade) was purchased from Fisher Scientific Corporation (Loughborough, UK); ultrapure water was produced by a Milli-Q Ultra-pure water system (Millipore Corporation, MA, USA); Leucine-enkephalin was purchased from SIGMA Corporation (USA). All other reagents were of analytical grade.

\section{Preparation of Extraction for UHPLC-ESI-Q-TOF-MS/MS Analysis}

Collection and preparation of plant samples: Fine powder $(150 \mathrm{mg})$ and $50 \mathrm{ml} 70 \%$ ethyl alcohol were placed into conical flasks and ultrasonically extracted for $1 \mathrm{~h}$, and the volume lost was replaced with fresh $70 \%$ ethyl alcohol. Finally, the supernatant was filtered with a $0.22 \mu \mathrm{m}$ microporous filter for UPLC analysis.

\section{Conditions of Analysis}

\section{Ultra-performance liquid chromatography}

Chromatographic separation was performed on an ACQUITY UPLC system (Waters Corporation, Milford, MA) consisting of a binary solvent manger, a sample manager and a column compartment. The column used was an UPLC ${ }^{\mathrm{TM}} \mathrm{BEH} \mathrm{C}_{25}$ column $(100 \mathrm{~mm} \times 2.1 \mathrm{~mm} 1.8 \mu \mathrm{m}$, Waters Corporation, Milford, USA). Column temperature was maintained at $40{ }^{\circ} \mathrm{C}$ for all analyses, Sample warehouse temperature at $10^{\circ} \mathrm{C}$. The optimal mobile phase consisted of a linear gradient system of (A) $0.1 \%$ formic acid in acetonitrile and (B) $0.1 \%$ formic acid in water: 0 to $1.5 \mathrm{~min}, 16$ to $22 \% \mathrm{~A} ; 1.5$ to $5 \mathrm{~min}, 22$ to $30 \% \mathrm{~A} ; 5$ to $9 \mathrm{~min}, 30$ to $40 \% A ; 9$ to $12 \mathrm{~min}, 40$ to $70 \% A ; 12$ to $15 \mathrm{~min}, 70$ to $100 \%$ A. The detection wavelengths 190 to $400 \mathrm{~nm}$ 
ultraviolet full wavelength scanning. The flow rate was set to $0.4 \mathrm{~mL} / \mathrm{min}$. Injection volume was $3 \mu \mathrm{L}$. The ultraviolet pectrophotometry of the positive and negative ions were performed through flowing straight to mass spectrometer. All the samples were kept at $4{ }^{\circ} \mathrm{C}$ during the analysis.

\section{Mass spectrometry.}

The positive ion ionization mode: the capillary voltage was $3.0 \mathrm{kV}$, the sampling cone voltage was $25 \mathrm{~V}$, the extraction voltage was $4.0 \mathrm{~V}$, the desolvation gas temperature was $350^{\circ} \mathrm{C}$, the desolvation gas flow was $600 \mathrm{~L} / \mathrm{h}$, the source temperature was $110^{\circ} \mathrm{C}$, and leucine enkephalin at a concentration of $0.2 \mathrm{ng} / \mathrm{mL}$ was used via a lock spray interface at a flow rate of $100 \mu l \cdot \mathrm{min}^{-1}$ for monitoring in positive ionization mode $([\mathrm{M}+\mathrm{H}]+=556.2771)$ to ensure accuracy during MS analysis. The lock spray frequency was set to 5 $\mathrm{s}$, and scan averaging for correction was every $0.02 \mathrm{~s}$ and $0.4 \mathrm{~s}$ per scan. The scanning range $\mathrm{was} \mathrm{m} / \mathrm{z}$ 100 1500.

The negative ion ionization mode: the capillary voltage was $2.2 \mathrm{kV}$, the sampling cone voltage was $25 \mathrm{~V}$, the extraction voltage was $3.5 \mathrm{~V}$, the desolvation gas temperature was $350^{\circ} \mathrm{C}$, the desolvation gas flow was $600 \mathrm{~L} / \mathrm{h}$, the source temperature was $110^{\circ} \mathrm{C}$, and leucine enkephalin at a concentration of $0.2 \mathrm{ng} / \mathrm{mL}$ was used via a lock spray interface at a flowrate of $100 \mu \mathrm{l} \cdot \mathrm{min}^{-1}$ for monitoring in negative ionization mode $([\mathrm{M}+\mathrm{H}]+=556.2771)$ to ensure accuracy during the MS analysis. The lock spray frequency was set to $5 \mathrm{~s}$, and scan averaging for correction was every $0.02 \mathrm{~s}$ and $0.4 \mathrm{~s}$ per scan. The scanning range was $\mathrm{m} / \mathrm{z}$ 100 1500.

\section{Declarations}

\section{Ethics approval and consent to participate}

Not applicable.

\section{Consent to publish}

Not applicable.

\section{Availability of data and materials}

The datasets used and/or analysed during the current study are available from the corresponding author on reasonable request.

\section{Competing interests}

The authors declare that they have no competing interests.

\section{Funding}

The authors wish to thank for providing financial supports from National Natural Science 
Foundation of China (81573523), Heilongjiang Touyan Innovation Team Program. The

funding bodies listed played no role in the design of the study, collection, analysis, and interpretation of data and in writing the manuscript.

\section{Authors' Contributions}

\section{Acknowledgements}

The authors wish to thank for providing financial supports from National Natural Science

Foundation of China (81573523), Heilongjiang Touyan Innovation Team Program.

\section{Abbreviations}

PCA: principal components analysis;OPLS-DA:orthogonal partial least squre -discriminate analysis; VIP: variable importance in the projection; RT: retention time.

\section{References}

[1] Pallavi S, Bhushan JA, Shanker D R, Mohammad P. Reactive Oxygen Species, Oxidative Damage, and Antioxidative Defense Mechanism in Plants under Stressful Conditions. Journal of Botany. 2012; 2012:126.

[2] Considine MJ, María Sandalio Luisa, Christine HF. Unravelling how plants benefit from ROS and NO reactions, while resisting oxidative stress. Annals of Botany. 2015;116: 469-73.

[3] Forman HJ, Maiorino M, Ursini FS. Signaling functions of reactive oxygen species. Biochemistry. 2010;49:835-42.

[4] Czarnockaa W, Stanisław Karpińskia. Friend or foe? Reactive oxygen species production, scavenging and signaling in plant response to environmental stresses. Free Radical Biology and Medicine. 2018;122:4-20

[5] Jun Y, Zhulong C. ROS Regulation During Abiotic Stress Responses in Crop Plants. Frontiers in Plant Science. 2015;6:1092.

[6] Mittler R. ROS are good. Trends in Plant Science. 2017;22: 11-9.

[7] Del Río LA, López-Huertas E. ROS generation in peroxisomes and its role in cell signaling. Plant and Cell Physiology. 2016;57:1364-76.

[8] Elstner EF. Mechanisms of oxygen activation in different compartments of plant cells. Current Topics in Plant Physiology. 1991;15:342-3. 
[9] Dat J,Vandenabeele S,E.Vranová, Montagu MV, D. Inzé, Breusegem FV. Dual action of the active oxygen species during plant stress responses. Cellular and Molecular Life Sciences CMLS. 2000;57: 77995.

[10] Qin YM, Hu CY, Zhu YX. The ascorbate peroxidase regulated by $\mathrm{H}_{2} \mathrm{O}_{2}$ and ethylene is involved in cotton fiber cell elongation by modulating ROS homeostasis. Plant Signaling \& Behavior. 2008;3: 194-6.

[11] Matilla-Vázquez MA, Angel Jesús Matilla. Role of H2O2 as Signaling Molecule in Plants. In: Ahmad P., Prasad M. (eds) Environmental Adaptations and Stress Tolerance of Plants in the Era of Climate Change. New York:Springer;2014. p.361-80.

[12] Baxter A, Mittler R, Suzuki N. ROS as key players in plant stress signalling. Journal of Experimental Botany. 2014;65:1229-40.

[13] Shi YH,Xie ZY,Wang R,Huang SJ,Li YM,Wang ZT.Quantitative and Chemical Fingerprint Analysis for the Quality Evaluation of Isatis indigotica based on Ultra-Performance Liquid Chromatography with Photodiode Array Detector Combined with Chemometric Methods. International Journal of Molecular Sciences, 2012;13:9035-50.

[14] Lin H,Zhu H,Tan J. Comprehensive investigation on metabolites of Wild-Simulated American Ginseng Root based on Ultra-high Performance Liquid Chromatography-Quadrupole Time-Of-Flight Mass Spectrometry. Journal of Agricultural and Food Chemistry. 2019.

[15] Xu J,Qian D,Jiang S,Guo J,Shang EX,Duan JA.UPLC-Q-TOF/MS for Analysis of the Metabolites of Flavone Glycosides from Scutellaria baicalensis Georgi by Human Fecal Flora in Vitro. Chromatographia. 2013;76:975-83.

[16] Lin H,Zhu H,Tan J,Wang H,Wang Z,Li P, et al.Comparative analysis of chemical constituents of moringa oleifera leaves from china and india by Ultra- performance Liquid Chromatography coupled with Quadrupole-Time-Of-Flight Mass Spectrometry. Molecules. 2019;24.

[17] Kliebenstein DJ.Secondary metabolites and plant/environment interactions: A view through Arabidopsis thaliana tinged glasses. Plant Cell and Environment. 2004;27:675-84.

[18] Gao Z,Huang K,Yang X,Xu H.Free radical scavenging and antioxidant activities of flavonoids extracted from the radix of Scutellaria baicalensis Georgi. Biochimica et Biophysica Acta. 1999; 1472: 643-50.

[19] Zhao T,Tang H,Xie L,Zheng Y ,Li X.Scutellaria baicalensis Georgi. (Lamiaceae): a review of its traditional uses, botany, phytochemistry, pharmacology and toxicology: A review of Scutellaria baicalensis Georgi. Journal of Pharmacy and Pharmacology. 2019. 
[20] Lin C,Mei H,Li-min Y,Yang L,Zhuo S,Tao Z.Changes in the physiological characteristics and baicalin biosynthesis metabolism of Scutellaria baicalensis Georgi. under drought stress.Industrial Crops Products. 2018;122: 473-82.

[21] Shulaev V,Cortes D,Miller G,Mittler R. Metabolomics for plant stress response. Physiologia Plantarum. 2008; 132:199-208.

[22] Sumner LW, Mendes P, Dixon RA. Plant metabolomics: large-scale phytochemistry in the Functional Genomics Era. Phytochemistry. 2003;62:817-36.

[23] Obata T, Fernie A.The use of metabolomics to dissect plant responses to abiotic stresses. Cellular \& Molecular Life Sciences. 2012; 69:3225-43.

[24] Jorge TF, João A,Rodrigues Caldana C, Schmidt , Carla António. Mass spectrometry-based plant metabolomics: metabolite responses to abiotic stress. Mass Spectrometry Reviews. 2015;35:620-49.

[25] Huimin G,Xiaoying F,Hongwei D,Wei C, Xiangcai M. Sodium dithionite-enhanced quality of radix scutellariae through modification of secondary metabolism. International Journal of Pharmaceutics. $2016 ; 6: 225-30$.

[26] Qi S,Huiru G,Jiahui W,Aihua Z,Xiangcai M. Exogenous intervention with sodium hydrosulfite enhances the quality of Radix Scutellariae by modulating antioxidases and secondary metabolities. Pharmacognosy Magazine. 2019;15:107-14.

[27] Hyun J,Woo Y, Hwang DS,Jo G,Eom S,Lee Y, et al. Relationships between structures of hydroxyflavones and their antioxidative effects. Bioorganic Medicine Chemistry Letters. 2010;20:5510-3.

[28] Ran L,Chang-Hui C,Xi-Cheng Al, Jian-Ping Z. Structural Origins of the Differential Antioxidative Activities between Baicalein and Baicalin. Chinese Journal of Magnetic Resonance. 2010; 27:132-40.

[29] Hongyan W,Kwok-Min H,Yingjie C,Suixu X,J Tze-Fei W,Hong X.Structure-activity relationships of flavonoids, isolated from Scutellaria baicalensis, binding to benzodiazepine site of GABA(A)receptor complex. Planta Medica. 2002;68:1059-62

[30] Li K,Fan H,Yin P,Yang L,Liu Y.Structure-activity relationship of eight high content flavonoids analyzed with a preliminary assign-score method and their contribution to antioxidant ability of flavonoids-rich extract from Scutellaria baicalensis shoots. Arabian Journal of Chemistry. 2018;11:159-70

[31] Feng Z,Zhou J,Shang X,Kuang G,Zhang L.Comparative research on stability of baicalin and baicalein administrated in monomer and total flavonoid fraction form of Radix scutellariae in biological fluids in vitro. Pharmaceutical Biology. 2017; 55: 1177-84.

[32] Perez CA,Wei Y,Guo M.Iron-binding and anti-fenton properties of baicalein and baicalin. Journal of Inorganic Biochemistry. 2009;103:326-32. 


\section{Table}

Table 1. Characterization of compounds in fresh Scutellaria root extract by UPLC-HDMS 


\begin{tabular}{|c|c|c|c|c|c|c|c|c|}
\hline $\begin{array}{l}\text { Peak } \\
\text { No. }\end{array}$ & Rt $(\min )$ & $\begin{array}{l}\text { Selected } \\
\text { ion }\end{array}$ & $\begin{array}{l}\text { Measured } \\
\operatorname{mass}(\mathrm{m} / \mathrm{z})\end{array}$ & $\begin{array}{c}\text { Calc.mass } \\
(\mathrm{m} / \mathrm{z})\end{array}$ & $\begin{array}{l}\text { Error } \\
(\mathrm{ppm})\end{array}$ & Formula & $\begin{array}{l}\text { MS/MS fragment } \\
\text { ion } \square \mathrm{m} / \mathrm{z})\end{array}$ & Identification \\
\hline 1 & 0.54 & {$[\mathrm{M}-\mathrm{H}]^{-}$} & 173.15 & 173.03 & 3.3 & $\mathrm{C}_{7} \mathrm{H}_{11} \mathrm{O}_{5}$ & $155,137,111$ & Shikimic Acid \\
\hline 2 & 0.62 & {$[\mathrm{M}-\mathrm{H}]^{-}$} & 191.14 & 191.15 & 2.9 & $\mathrm{C}_{6} \mathrm{H}_{7} \mathrm{O}_{7}$ & 173,147 & Citric acid \\
\hline \multirow[t]{2}{*}{3} & 2.17 & {$[\mathrm{M}+\mathrm{H}]^{+}$} & 305.26 & 305.21 & 4.0 & $\mathrm{C}_{15} \mathrm{H}_{13} \mathrm{O}_{7}$ & 287,153 & $\begin{array}{l}3,5,7,2 \text { ',6'- } \\
\text { Pentahydroxyflavanone }\end{array}$ \\
\hline & & {$[\mathrm{M}-\mathrm{H}]^{-}$} & 303.25 & 303.19 & 3.5 & $\mathrm{C}_{15} \mathrm{H}_{11} \mathrm{O}_{7}$ & & \\
\hline \multirow[t]{2}{*}{4} & 2.8 & {$[\mathrm{M}+\mathrm{H}]^{+}$} & 549.15 & 549.16 & 1.6 & $\mathrm{C}_{26} \mathrm{H}_{29} \mathrm{O}_{13}$ & $531,513,495411,375$ & $\begin{array}{l}\text { Aspenin-6-C- } \\
\text { Arabinose-8-C- } \\
\text { glucoside }\end{array}$ \\
\hline & & {$[\mathrm{M}-\mathrm{H}]^{-}$} & 547.14 & 547.14 & 1.3 & $\mathrm{C}_{26} \mathrm{H}_{27} \mathrm{O}_{13}$ & & \\
\hline \multirow[t]{2}{*}{5} & 3.19 & {$[\mathrm{M}+\mathrm{H}]^{+}$} & 549.15 & 549.16 & 0.9 & $\mathrm{C}_{26} \mathrm{H}_{29} \mathrm{O}_{13}$ & $531,513,495411,375$ & $\begin{array}{l}\text { Chrysin-6-C-glucose-8- } \\
\text { C-Araboside }\end{array}$ \\
\hline & & {$[\mathrm{M}-\mathrm{H}]^{-}$} & 547.14 & 547.14 & 2.7 & $\mathrm{C}_{26} \mathrm{H}_{27} \mathrm{O}_{13}$ & & \\
\hline \multirow[t]{2}{*}{6} & 4.16 & {$[\mathrm{M}+\mathrm{H}]^{+}$} & 477.10 & 477.10 & 2.1 & $\mathrm{C}_{22} \mathrm{H}_{21} \mathrm{O}_{12}$ & 301,286 & $\begin{array}{l}5,7,2 \text { '-trihydroxy-6- } \\
\text { methoxyflavonoids-7-O- } \\
\text { glucuronide }\end{array}$ \\
\hline & & {$[\mathrm{M}+\mathrm{H}]^{-}$} & 475.08 & 475.08 & 0.2 & $\mathrm{C}_{22} \mathrm{H}_{19} \mathrm{O}_{12}$ & & \\
\hline 7 & 4.35 & {$[\mathrm{M}-\mathrm{H}]^{-}$} & 287.26 & 287.19 & 2.6 & $\mathrm{C}_{15} \mathrm{H}_{11} \mathrm{O}_{6}$ & 251,135 & Eriodictyol \\
\hline \multirow[t]{2}{*}{8} & 4.56 & {$[\mathrm{M}+\mathrm{H}]^{+}$} & 347.07 & 347.07 & 4 & $\mathrm{C}_{17} \mathrm{H}_{15} \mathrm{O}_{8}$ & 332,314 & $\begin{array}{l}5,7,2 ', 5 \text { '- tetrahydroxy } \\
-8,6^{\prime} \text { - dimethyl } \\
\text { oxyflavones }\end{array}$ \\
\hline & & {$[\mathrm{M}-\mathrm{H}]^{-}$} & 345.05 & 345.06 & 2.6 & $\mathrm{C}_{17} \mathrm{H}_{13} \mathrm{O}_{8}$ & & \\
\hline 9 & 4.92 & $\begin{array}{l}{[\mathrm{M}+\mathrm{H}]^{+}} \\
{[\mathrm{M}-\mathrm{H}]^{-}}\end{array}$ & 447.12 & 447.09 & 2.5 & $\mathrm{C}_{21} \mathrm{H}_{19} \mathrm{O}_{11}$ & 271,253 & Baicalin \\
\hline \multirow[t]{2}{*}{10} & 5.68 & {$[\mathrm{M}+\mathrm{H}]^{+}$} & 447.09 & 447.09 & 4 & $\mathrm{C}_{21} \mathrm{H}_{19} \mathrm{O}_{11}$ & 285 & $\begin{array}{l}\text { Oroxylin A-5-O } \\
\text { glucoside }\end{array}$ \\
\hline & & {$[\mathrm{M}-\mathrm{H}]^{-}$} & 445.07 & 445.07 & 2.2 & $\mathrm{C}_{21} \mathrm{H}_{17} \mathrm{O}_{11}$ & & \\
\hline \multirow[t]{2}{*}{11} & 5.83 & {$[\mathrm{M}+\mathrm{H}]^{+}$} & 447.09 & 447.09 & 4.7 & $\mathrm{C}_{21} \mathrm{H}_{19} \mathrm{O}_{11}$ & 271 & Baicalin isomers \\
\hline & & {$[\mathrm{M}-\mathrm{H}]^{-}$} & 445.07 & 445.07 & 1.8 & $\mathrm{C}_{21} \mathrm{H}_{17} \mathrm{O}_{11}$ & & \\
\hline \multirow[t]{2}{*}{12} & 5.95 & {$[\mathrm{M}+\mathrm{H}]^{+}$} & 477.10 & 477.10 & 4.2 & $\mathrm{C}_{22} \mathrm{H}_{21} \mathrm{O}_{12}$ & 301,286 & $\begin{array}{l}\text { 5,7,8-trihydroxy-6- } \\
\text { methoxyflavone-7-O- } \\
\text { glucuronide }\end{array}$ \\
\hline & & {$[\mathrm{M}-\mathrm{H}]^{-}$} & 475.08 & 475.08 & 4.4 & $\mathrm{C}_{22} \mathrm{H}_{19} \mathrm{O}_{12}$ & & \\
\hline \multirow[t]{2}{*}{13} & 6.19 & {$[\mathrm{M}+\mathrm{H}]^{+}$} & 461.10 & 461.10 & 4.6 & $\mathrm{C}_{22} \mathrm{H}_{21} \mathrm{O}_{11}$ & 285,270 & Wogonoside \\
\hline & & {$[\mathrm{M}-\mathrm{H}]^{-}$} & 459.09 & 459.09 & 3 & $\mathrm{C}_{22} \mathrm{H}_{19} \mathrm{O}_{11}$ & & \\
\hline 14 & 6.2 & {$[\mathrm{M}-\mathrm{H}]^{-}$} & 429.08 & 429.08 & 3.5 & $\mathrm{C}_{21} \mathrm{H}_{17} \mathrm{O}_{10}$ & 253 & $\begin{array}{l}\text { Chrysin -7-O- } \\
\text { glucuronide }\end{array}$ \\
\hline \multirow[t]{2}{*}{15} & 6.44 & {$[\mathrm{M}+\mathrm{H}]^{+}$} & 477.10 & 477.10 & 2.9 & $\mathrm{C}_{22} \mathrm{H}_{21} \mathrm{O}_{12}$ & 301 & $\begin{array}{l}\text { 5,6,7-trihydroxy-8- } \\
\text { methoxyflavone-7-O- } \\
\text { glucuronide }\end{array}$ \\
\hline & & {$[\mathrm{M}-\mathrm{H}]^{-}$} & 475.08 & 475.08 & 3.2 & $\mathrm{C}_{22} \mathrm{H}_{19} \mathrm{O}_{12}$ & & \\
\hline 16 & 7.01 & {$[\mathrm{M}+\mathrm{H}]^{+}$} & 315.30 & 315.22 & 1.1 & $\mathrm{C}_{17} \mathrm{H}_{15} \mathrm{O}_{6}$ & 282,285 & $\begin{array}{l}\text { 5,8-dihydroxy-6,7- } \\
\text { dimethoxyflavones }\end{array}$ \\
\hline 17 & 7.05 & {$[\mathrm{M}-\mathrm{H}]^{-}$} & 489.09 & 489.10 & 0.8 & $\mathrm{C}_{23} \mathrm{H}_{21} \mathrm{O}_{12}$ & 313,298 & $\begin{array}{l}\text { 5,7-dihydroxy-6,8- } \\
\text { dimethoxyflavone-7-O- } \\
\text { glucuronide }\end{array}$ \\
\hline 18 & 7.97 & {$[\mathrm{M}-\mathrm{H}]^{-}$} & 329.88 & 329.85 & 3.5 & $\mathrm{C}_{17} \mathrm{H}_{13} \mathrm{O}_{7}$ & 299 & $\begin{array}{l}5,2^{\prime}, 6^{\prime}-\text { Trihydroxy-7,8- } \\
\text { dimethoxyflavone }\end{array}$ \\
\hline \multirow[t]{2}{*}{19} & 8.21 & {$[\mathrm{M}+\mathrm{H}]^{+}$} & 271.05 & 271.06 & 3.6 & $\mathrm{C}_{15} \mathrm{H}_{11} \mathrm{O}_{5}$ & 253,241 & Baicalein \\
\hline & & {$[\mathrm{M}-\mathrm{H}]^{-}$} & 269.04 & 269.04 & 1.9 & $\mathrm{C}_{15} \mathrm{H}_{9} \mathrm{O}_{5}$ & & \\
\hline \multirow[t]{2}{*}{20} & 10.51 & {$[\mathrm{M}+\mathrm{H}]^{+}$} & 285.05 & 285.07 & 4.6 & $\mathrm{C}_{16} \mathrm{H}_{13} \mathrm{O}_{5}$ & 270 & Wogonin \\
\hline & & {$[\mathrm{M}-\mathrm{H}]^{-}$} & 283.04 & 283.06 & 4.2 & $\mathrm{C}_{16} \mathrm{H}_{11} \mathrm{O}_{5}$ & & \\
\hline \multirow[t]{2}{*}{21} & 10.67 & {$[\mathrm{M}+\mathrm{H}]^{+}$} & 255.06 & 255.06 & 4.5 & $\mathrm{C}_{15} \mathrm{H}_{11} \mathrm{O}_{4}$ & 209 & Chrysin \\
\hline & & {$[\mathrm{M}-\mathrm{H}]^{-}$} & 253.04 & 253.05 & 3.5 & $\mathrm{C}_{15} \mathrm{H}_{9} \mathrm{O}_{4}$ & & \\
\hline 22 & 11.01 & {$[\mathrm{M}+\mathrm{H}]^{+}$} & 375.10 & 375.18 & 4.3 & $\mathrm{C}_{19} \mathrm{H}_{19} \mathrm{O}_{8}$ & $360,345,327$ & Skullcapflavone $\square$ \\
\hline \multirow[t]{2}{*}{23} & 11.05 & {$[\mathrm{M}+\mathrm{H}]^{+}$} & 375 & 375 & 1.1 & $\mathrm{C}_{19} \mathrm{H}_{19} \mathrm{O}_{8}$ & 345 & $\begin{array}{l}\text { 5,7-dihydroxy-6,8,2',3'- } \\
\text { tetramethoxyflavones }\end{array}$ \\
\hline & & {$[\mathrm{M}-\mathrm{H}]-$} & 373 & \multicolumn{4}{|c|}{ ge $12 / 17$} & \\
\hline
\end{tabular}




24 \begin{tabular}{rlllll}
11.45 & {$[\mathrm{M}+\mathrm{H}]^{+}$} & 345.0 & 345.09 & 4.3 & $\mathrm{C}_{19} \mathrm{H}_{17} \mathrm{O}_{8}$ \\
$\mathrm{C}_{25} \mathrm{H}_{17} \mathrm{O}_{7}$ & 330,315 & $\begin{array}{l}\text { 5,2-dihydroxy-6,7,8- } \\
\text { trimethoxyflavones }\end{array}$ \\
{$[\mathrm{M}-\mathrm{H}]^{-}$} & 343.07 & 343.08 & 1.9 & $\mathrm{C}_{25} \mathrm{H}_{15} \mathrm{O}_{7}$ & \\
\hline
\end{tabular}

\section{Figures}

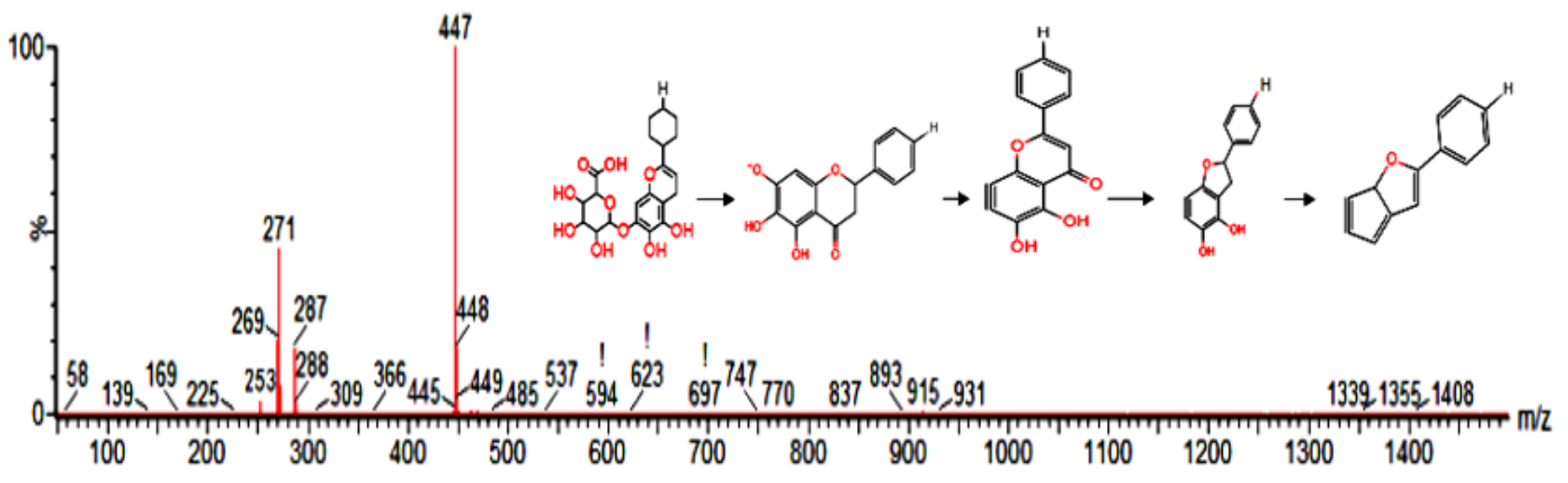

Figure 1

MS-MS and the proposed framentation pathway of baicalin

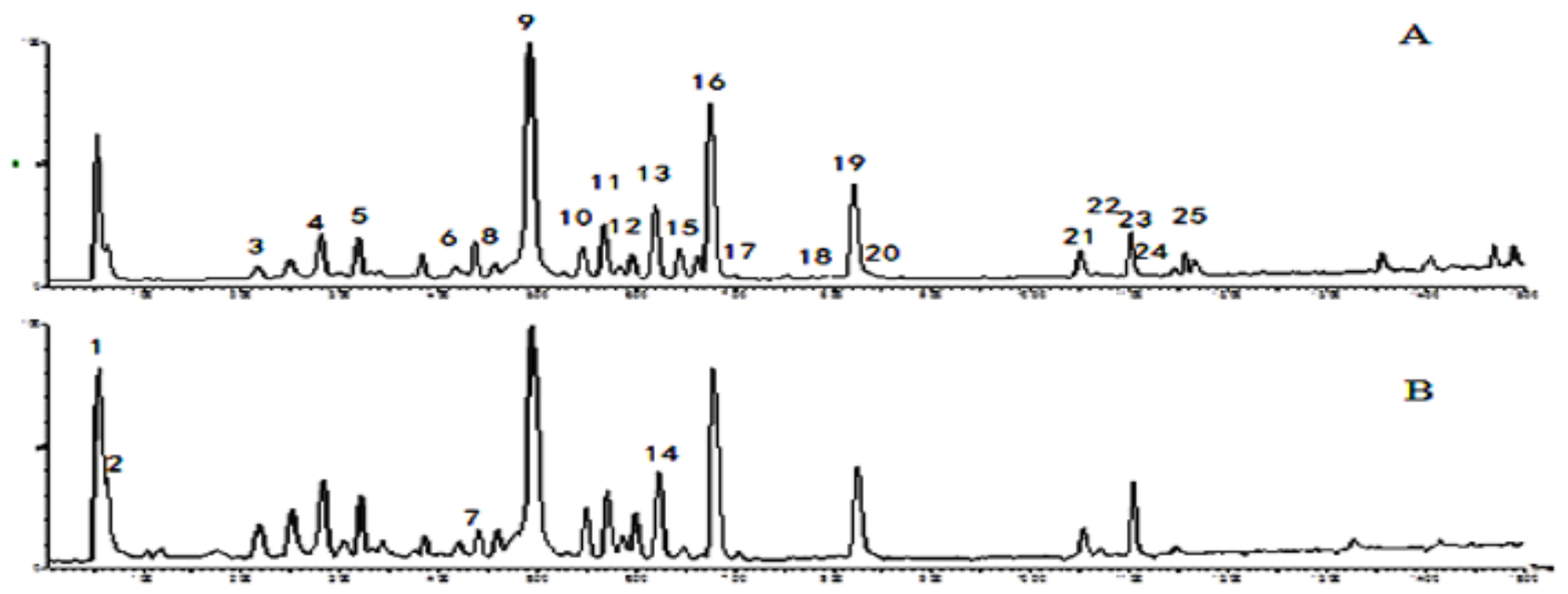

Figure 2

Chromatograms of Scutellaria root in positive ion mode and in negative ion mode. (A)positive ion mode ; (B) negative ion mode. 


\section{Scores Comp[1] vs. Comp[2] colored by Condition}

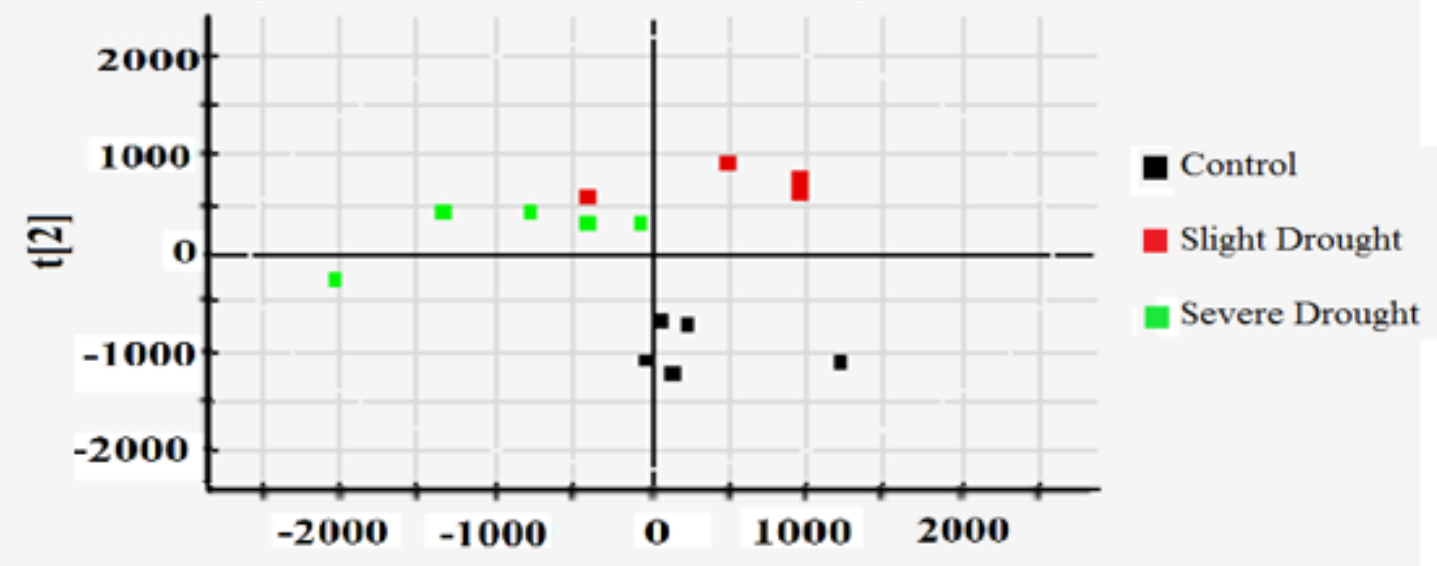

Figure 3

PCA score diagram of UPLC-Q/TOF-MS data PCA analysis in positive ion mode

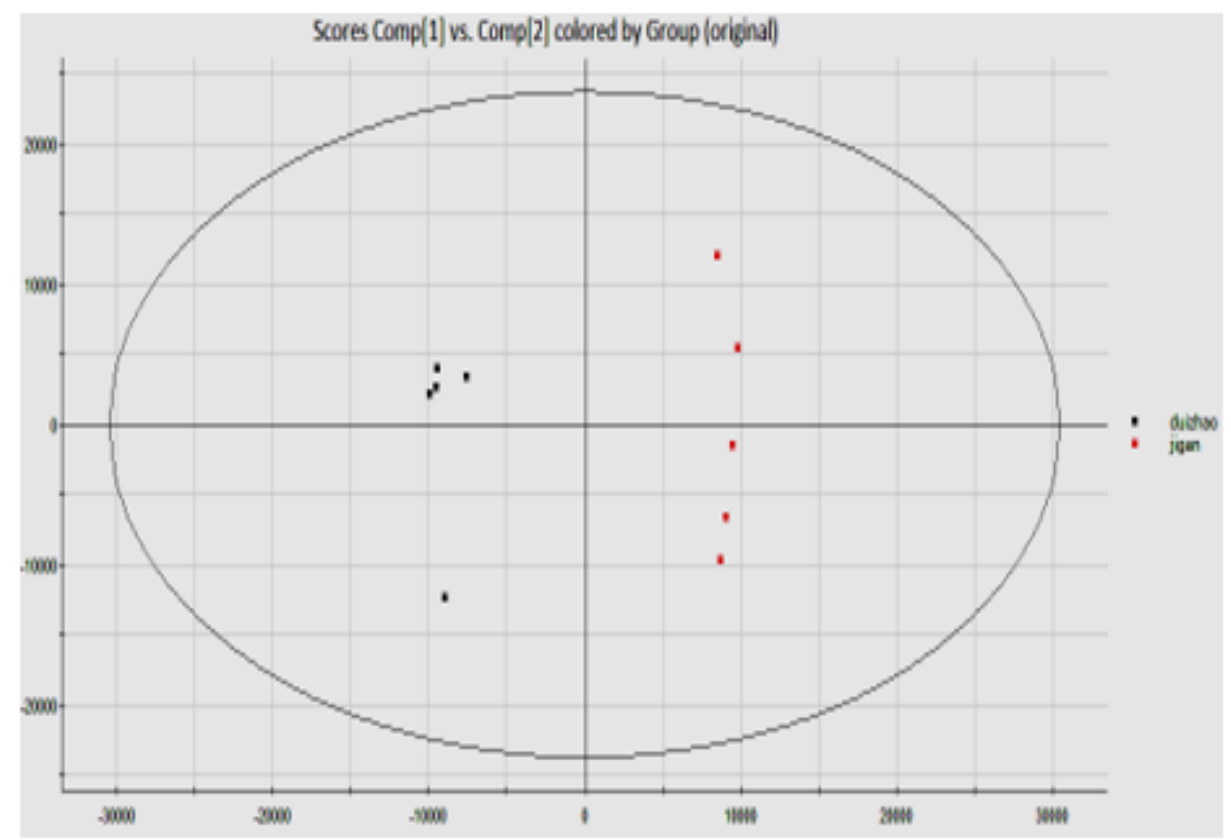

Figure 4

OPLS-DA analysis between severe drought treatment and control in positive ion mode. 


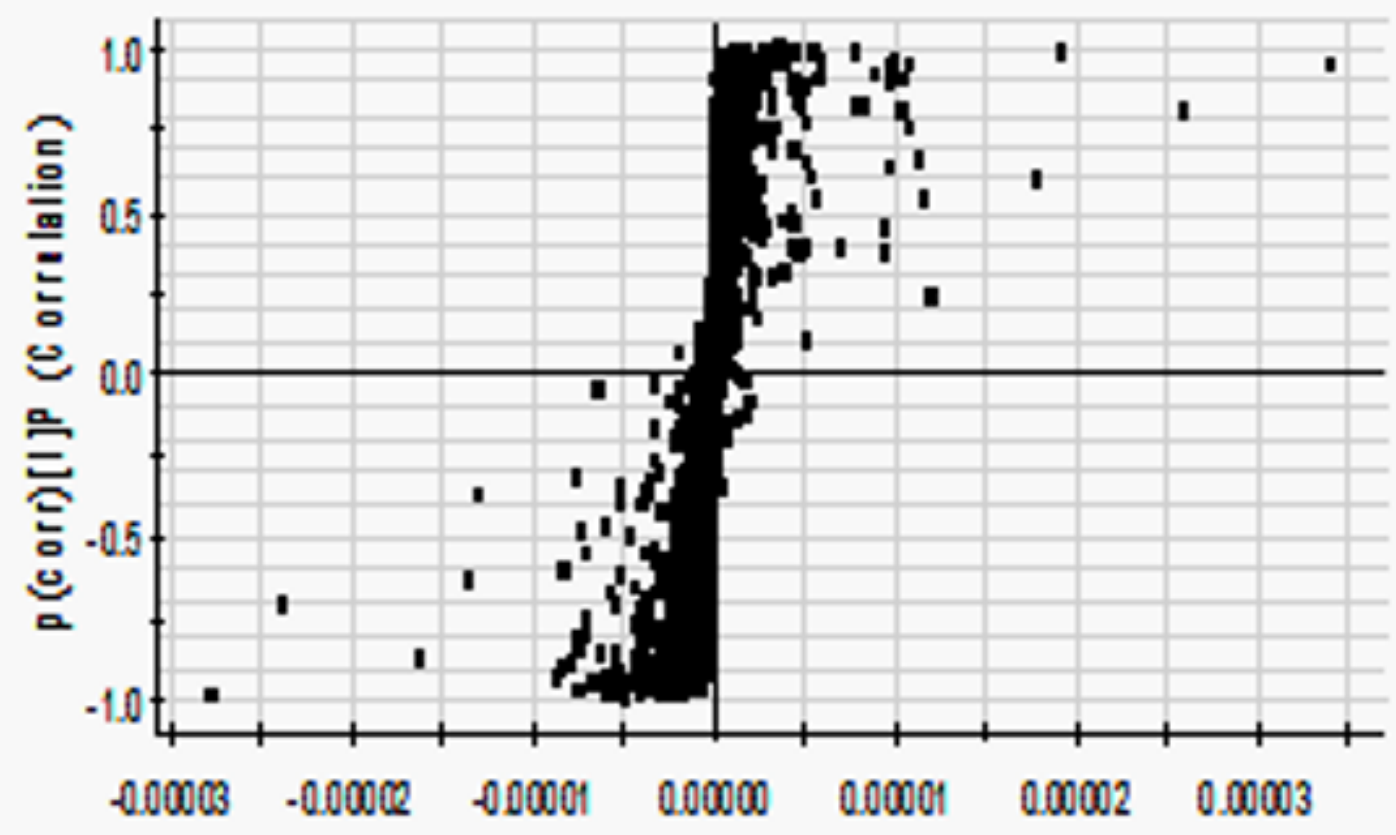

Figure 5

S-plot of the OPLS-DA analysis between severe drought and control in positive ion mode. Most of varied compounts were secondary metabolites with polyphenolic hydroxyl group, without a sugar moiety, showing increased activities. A: Citric acid; B: Shikimic Acid; C: Baicalin; D: Wogonoside; E: Baicalein; F: Wogonin; G: 3,5,7,2',6'-Pentahydroxyflavanone; H: 5,2',6'-Trihydroxy-7,8-dimethoxyflavone; I: Chrysin; J: Eriodictyol; K: 5,8-Dihydroxy-6,7-dimethoxyflavone. C: Control D1: Slight Drought D2: Svere Drought 

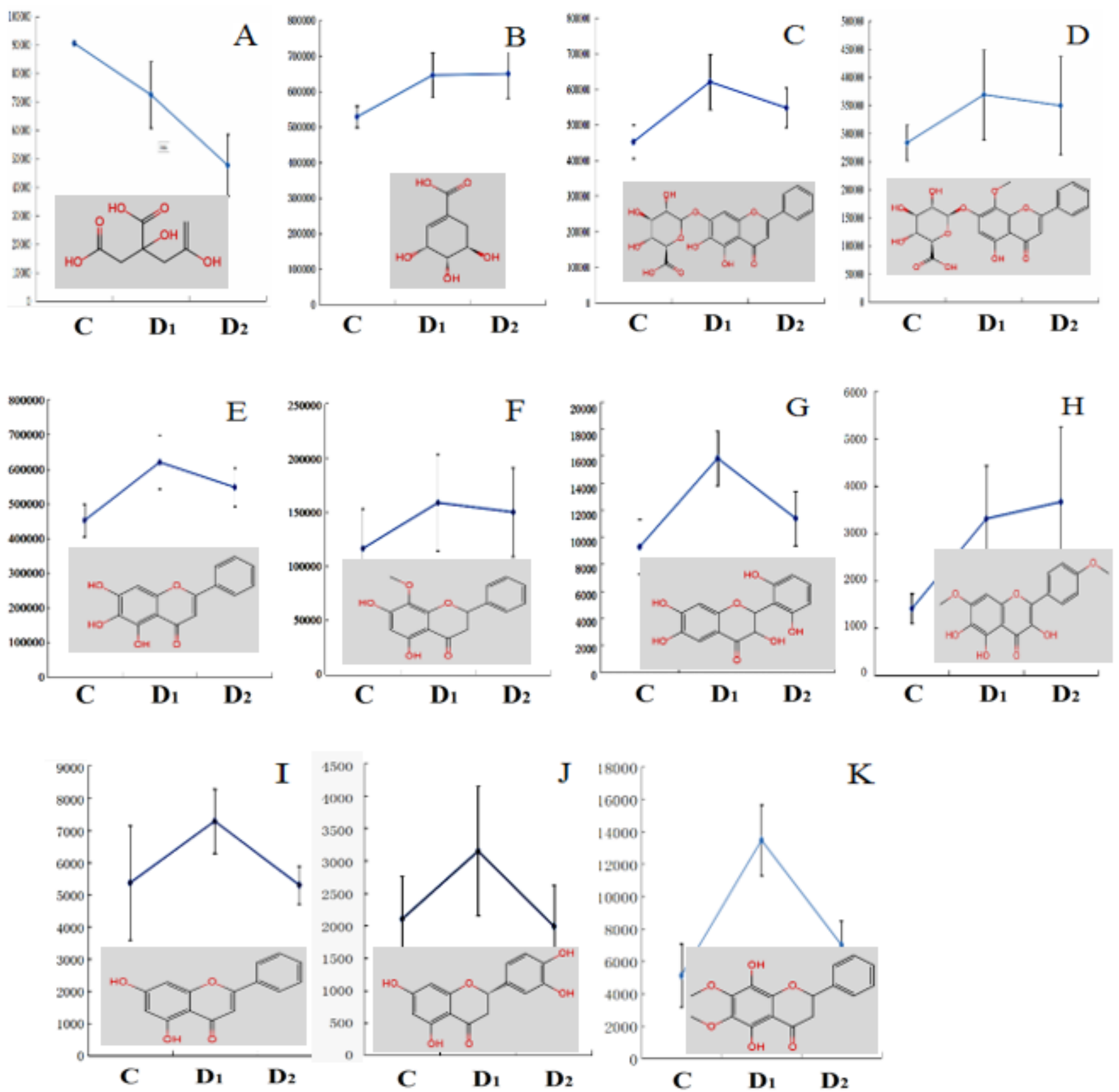

Figure 6

Change of 11 compounds under drought 


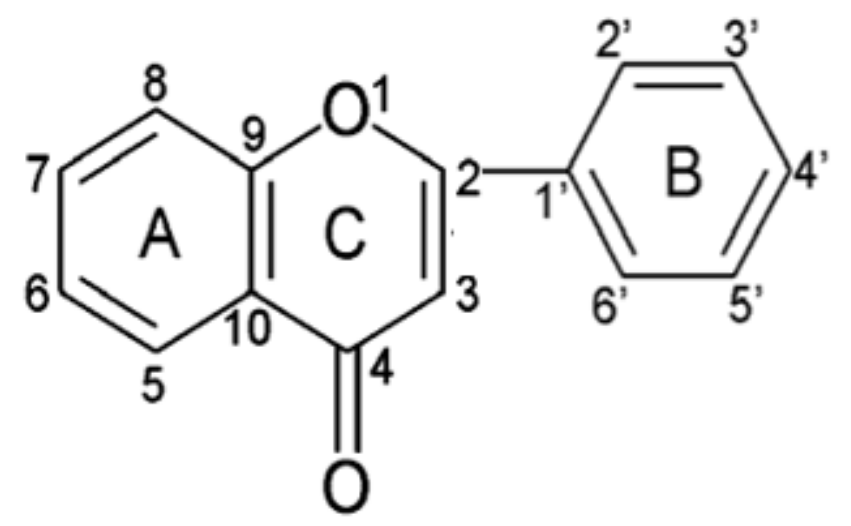

Figure 7

Molecular structure diagram of the flavonoids 